\title{
ENSAIOS
}

\section{A ESTABILIDADE DA EMPREGADA DOMÉSTICA DURANTE A GRAVIDEZ: UM DIREITO FUNDAMENTAL TARDIAMENTE CONCEDIDO}

\section{Domingos Sávio Zainaghi}

Desde 19 de julho de 2006, vige a Lei n. 11.324, que alterou dispositivos de legislações anteriores que tratavam do trabalho doméstico.

Falou-se muito sobre a não obrigatoriedade de o empregador recolher à conta de FGTS dos empregados, como se este fosse o grande direito que os trabalhadores domésticos haviam perdido com a novel legislação.

Ocorre, entretanto, que se deu mais atenção ao direito não concedido, do que àquele concedido, do qual trataremos neste ensaio.

Desde a promulgação da Constituição de 1988, sempre causou certa indignação o fato de o constituinte não ter concedido à trabalhadora doméstica a estabilidade no emprego durante a gravidez.

Com efeito, os direitos dos trabalhadores domésticos estão previstos no parágrafo único do art. 7. da Constituição da República:

Art. $7 \ldots$

Parágrafo único. São assegurados à categoria dos trabalhadores domésticos os direitos previstos nos incisos IV, VI, VIII, XV, XVII, XVIII, XIX, XXI e XXIV, bem como a sua integração à previdência social.

E os incisos acima citados assim prevêem:

Art. $7^{\circ}$

IV - salário mínimo, fixado em lei, nacionalmente unificado, capaz de atender a suas necessidades vitais básicas e às de sua família com moradia, alimentação, educação, saúde, lazer, vestuário, higiene, transporte e previdência social, com reajustes periódicos que lhe preservem o poder aquisitivo, sendo vedada sua vinculação para qualquer fim;

VI - irredutibilidade do salário, salvo o disposto em convenção ou acordo coletivo; 
VIII - décimo terceiro salário com base na remuneração integral ou no valor da aposentadoria;

XV - repouso semanal remunerado, preferencialmente aos domingos;

XVII - gozo de férias anuais remuneradas com, pelo menos um terço a mais que o salário normal;

XVIII - licença à gestante, sem prejuízo do emprego e do salário, com a duração de cento e vinte dias;

XIX - licença-paternidade, nos termos fixados em lei;

XXI - aviso prévio proporcional ao tempo de serviço, sendo no mínimo de trinta dias nos termos da lei;

XXIV - aposentadoria

Vê-se que não faz parte do rol supra, a previsão do inciso I, do mesmo artigo, o qual tem a seguinte redação: "I - relação de emprego protegida contra despedida arbitrária ou sem justa causa, nos termos de lei complementar, que preverá indenização compensatória, dentre outros direitos;". E no Ato das disposições Constitucionais Transitórias, tem-se a regulamentação do inciso I, do artigo 7, assim prevendo:

Art. 10. Até que seja promulgada a lei complementar a que se refere o art. $7^{\circ}$, I, da Constituição:

II - fica vedada a dispensa arbitrária ou sem justa causa:

a)...

b) da empregada gestante, desde a confirmação da gravidez até cinco meses após o parto.

Portanto, ficava claro que não havia o constituinte de 1988 concedido à empregada doméstica a estabilidade durante a gravidez, direito restringido às trabalhadoras urbanas e rurais.

Para os menos atentos, o salário, com a duração de cento e vinte dias, seria a garantia de estabilidade.

A licença à gestante é um direito previdenciário e não propriamente trabalhista.

Nos ensinamentos de Carlos Henrique Bezerra Leite "a licença à gestante consiste num repouso com duração de 120 dias (e aqui a novidade em relação ao regime anterior 
que era de 90 dias) concedido à empregada, à trabalhadora avulsa e à doméstica antes e depois do parto".

Durante o repouso, a trabalhadora percebe um benefício previdenciário chamado de salário-maternidade, não podendo ser despedida de forma arbitrária ou sem justa causa.

Para a segurada empregada e a trabalhadora avulsa consistirá numa renda igual à remuneração mensal, efetivando-se a compensação quando do recolhimento das contribuições previdenciárias, a cargo do empregador ou do tomador de serviço (Lei n. 8.213/91, art. 72). O salário-maternidade da trabalhadora doméstica é pago diretamente pela Previdência Social (Lei n. 8.213/91, art. 73). (Constituição e Direitos Sociais dos Trabalhadores. LTr, pág. 88)

E os artigos 72 e 73 da Lei n. ${ }^{\circ}$ 8.213/91, que é a lei de benefícios da Previdência Social, não deixavam dúvidas quanto ao caráter previdenciário desse direito:

Art. 72. O salário-maternidade para a segurada empregada ou trabalhadora avulsa consistirá numa renda mensal igual à sua remuneração integral.

Art. 73. Assegurado o valor de um salário mínimo, o saláriomaternidade para as demais seguradas consistirá:

I - em um valor correspondente ao seu último salário-decontribuição, para a segurada empregada doméstica;

II - em um doze avos do valor sobre o qual incidiu sua última contribuição anual, para a segurada especial;

III - em um doze avos da soma dos doze últimos salários-decontribuição, apurados em um período não superior a quinze meses, para as demais seguradas.

E os tribunais assim se pronunciavam quanto ao tema:

Inexistência de direito à reintegração, com base no art. 10, II, b, $\mathbb{1} 1^{\circ}$, nas disposições transitórias. Os trabalhadores domésticos não gozam de todos os direitos previstos no art. $7^{\circ}$ da Magna Carta tendo esta assegurado, apenas, aqueles elencados nos incisos do parágrafo único do art. $7^{\circ}$. Ora, não se incluindo neles a proteção contra a despedida arbitrária ou sem justa causa (inciso I) é inviável buscar a proteção mínima já prevista no art. 10, II, b, $\int 1^{\circ}$, das disposições transitórias. Recurso improvido (Ac. TRT 15ª R. - RO 8.276/89);

Gestante - O parágrafo único do art. $7^{\circ}$ da Constituição Federal, que prevê os direitos dos trabalhadores domésticos, não inclui 
o inciso I desse artigo. Conseqüentemente, não se aplica aos domésticos o art. 10 das Disposições Constitucionais Transitórias, que trata entre outros direitos, da estabilidade da gestante (Ac. TRT 8a R. (DF) - RO 4.698/89);

A exaustiva enumeração dos direitos estendidos ao empregado doméstico contida no parágrafo único do art. $7^{\circ} \mathrm{da}$ Constituição Federal não contempla o de estabilidade provisória da gestante no período previsto no art. 10, inciso II, b, das Disposições Transitórias (Ac. TRT $4^{a}$ R. (RS) - RO 359/90);

A empregada doméstica, embora destinatária do saláriomaternidade, por força de preceito constitucional, não foi contemplada com a estabilidade provisória a que alude o art. 10, inciso II, b, do ADCT, em face da omissão do art. $7^{\circ}$, \ único, da $\mathrm{CF} / 88$ a respeito desta garantia. Obrigar uma família a manter o empregado doméstico, a pretexto de uma estabilidade provisória, quando a confiança deixa de existir, afronta o princípio da razoabilidade. E nem se diga que poderia a obrigação de fazer ser convertida em obrigação de dar. No serviço doméstico não há finalidade lucrativa, tampouco há risco da exploração de mão-de-obra, inexistindo, em conseqüência, o lucro ou o prejuízo decorrente desta exploração. Desta forma, seria um alto gravame ao orçamento familiar impor tal conversão. Estabilidade

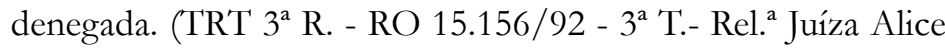
Monteiro de Barros - DJMG 12.11.1993);

Inaplicabilidade - A estabilidade provisória da gestante, prevista no Ato das Disposições Constitucionais Transitórias, é mero desdobramento do direito à proteção contra despedida arbitrária ou sem justa causa, portanto não se aplica à empregada doméstica, já que não se encontra entre os direitos expressamente assegurados àquela categoria pela Constituição Federal. Recurso improvido no particular por maioria. (TRT 24 R. - Ac. 0001290/ 97 - RO 0000167/97 - Rel. Juiz João de Deus Gomes de Souza - DJMS 20.06.1997, p.00051).

Mesmo quanto ao pagamento dos 120 dias quando o empregador tivesse despedido a empregada (por não gozar de estabilidade), a jurisprudência era no sentido de que caberia ao patrão, já que, com a dispensa da empregada, teria ele impedido que a trabalhadora pudesse receber o benefício previdenciário.

Ora, se não tinha o empregador obrigação legal de manter no emprego a empregada doméstica grávida, nunca nos pareceu correto o entendimento pretoriano.

Com o passar do tempo, até mesmo neste ponto o entendimento dos tribunais mudou: 
A norma constitucional prevista no art. $7^{\circ}$, inciso XVIII, com relação à categoria dos trabalhadores domésticos foi regulamentada no sentido de competir o pagamento do referido auxílio diretamente pela Previdência Social (Decreto n. ${ }^{\circ}$ 611, de 21 de julho de 1992, art. 98) e não pelo próprio empregador. Recurso desprovido. (TRT 3a R. - RO 14.066/91 - 4 a T. - Rel. Juiz Orestes Campos Gonçalves - DJMG 28.11.1992);

Empregada doméstica - Férias proporcionais - Gravidez - Salário maternidade. Não obstante as disposições da Lei n. ${ }^{0}$ 5.859/72 que rege a categoria dos domésticos, e das peculiaridades nela contidas, entendendo ser admissível o pagamento das férias proporcionais ao trabalhador doméstico, desde que compreendido o pedido, nos direitos básicos garantidos pela Constituição Federal de 1988, em nível de igualdade ao trabalhador urbano em geral. Denomina-se salário-maternidade o ingresso econômico assegurado à mulher durante o período de repouso obrigatório, por ocasião do parto, em nossa lei de 12 semanas. A mulher estará proibida de trabalhar durante este período e sem prejuízo da remuneração (Amauri Mascaro Nascimento). Logo, é a remuneração correspondente ao período de licença em razão da gravidez. Assim, a eventual dispensa em razão da prenhez não gera salário-maternidade. (TRT 10 R. RO 0377/99 - $3^{a}$ T. - Rel. Juiz Bertholdo Satyro - DJU 25.05.1999);

Doméstica - Salário-maternidade. Responsabilidade pelo pagamento. Como dispõe o art. $7^{\circ}$, $\int$ único, da $\mathrm{CF} / 88$, à categoria dos empregados domésticos não foi assegurado o direito à estabilidade preconizada pelo art. 10, II, b, do ADCT. Mesmo se residido o pacto em período coincidente com aquele reservado à percepção do salário-maternidade, pertencendo a responsabilidade pelo pagamento dessa vantagem à autarquia previdenciária (art. 71, da Lei n. ${ }^{\circ} 8.213 / 91$ ), nada há que se demandar em face da ex-empregadora. (10 ${ }^{a}$ R. - RO 4.471/99 - $3^{\mathrm{a}}$ T. - Rel. Juiz Douglas Alencar Rodrigues - DJU 03.03.2000);

Salário-maternidade - Doméstica. Dispensa imotivada. Irresponsabilidade patronal a partir de 23.03.1994. A partir de 23.03.1994, pela nova redação que a Lei n. ${ }^{\circ} 8.861 / 94$ deu aos arts. 71 a 73 da Lei n. ${ }^{\circ} 8.213 / 91$, o salário-maternidade de 120 dias, assegurado à empregada doméstica poderá ser requerido, por ela, no prazo de 90 dias após o parto, diretamente perante o órgão competente (INSS), ainda que extinto o contrato de trabalho, já que nos 12 meses posteriores conserva a condição de segurada conforme art. 15 da Lei n. ${ }^{\circ} 8.213 / 91$. O art. 95 do Decreto n. ${ }^{\circ}$ 611/92 do antigo regulamento os PBPS perdeu 
eficácia, porque em afronta às novas disposições da Lei n. ${ }^{\circ}$ 8.213/ 91, não pode mais ser aplicado, pois sendo o decreto espécie normativa inferior e por contrária a lei que regulamenta, não tem eficácia. A dispensa sem justa causa da empregada doméstica, no caso, é exercício regular de direito que não afronta o preceito do art. 120 do CCB. Assim, o empregador não responde pelo equivalente ao salário-maternidade, porque não frustrou a percepção ao benefício legal. (TRT 15 R. - Proc. 30.527/98 Ac. 10.572/00 - $2^{\mathrm{a}}$ T. - Rel. Juiz José Antônio Pacontti - DOESP 28.03.2000);

Empregada doméstica - Salário-maternidade. O Saláriomaternidade da empregada doméstica é devido pela Previdência Social, e não pelo empregador, ainda que dispensada a laborista sem justa causa, pois a norma legal não condiciona o pagamento do benefício à doméstica à vigência do contrato de trabalho. Esta a interpretação que se colhe do exame conjunto dos artigos do Decreto n. ${ }^{\circ} 2.172 / 97$, que tratam da matéria. (TRT $3^{\mathrm{a}} \mathrm{R}$. RO 11.799/98 - $1^{\text {a }}$ T. - Rel. Juíza Denise Alves Horta - DJMG 21.05.1999).

Logo, a estabilidade era de 120 dias, mas os salários desse período eram pagos pela Previdência Social, e não pelo empregador.

Agora, a Lei n. 11.324/06, atendendo aos reclamos de muitos, concedeu às trabalhadoras domésticas o mesmo direito, acrescendo à Lei n. 5.859/72 (Lei do trabalho doméstico), o artigo 4 A, o qual tem esta redação: “Art. 4-A. É vedada a dispensa arbitrária ou sem justa causa da empregada doméstica gestante desde a confirmação da gravidez até 5 (cinco) meses após o parto". Portanto, corrigiu-se uma discriminação da Constituição de 1988, concedendo-se às domésticas grávidas, os mesmos direitos das trabalhadoras urbanas e rurais. 